\title{
Anemia and Metabolic Acidosis as Risk Factor of Mortality in Children with Severe Acute Malnutrition
}

Katharina Yosephin Lakonawaa ${ }^{a}$ I Gusti Lanang Sidiartha ${ }^{b}$, I.G.A.P. Eka Pratiwi ${ }^{c}$

Manuscript submitted: 27 August 2020, Manuscript revised: 09 September 2020, Accepted for publication: 18 October 2020

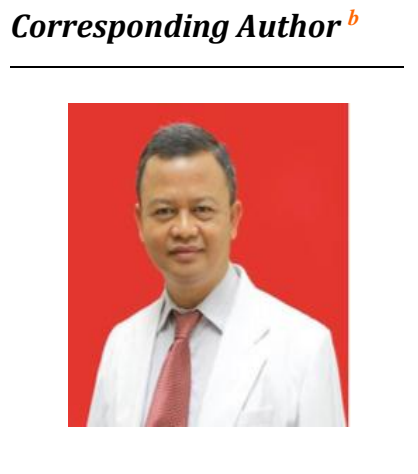

Keywords

acute malnutrition;

anemia;

marasmus;

metabolic acidosis;

mortality;

\begin{abstract}
Mortality is still high among children with severe acute malnutrition who require hospitalization. This study investigated the factors independently related to the mortality among hospitalized children with severe acute malnutrition. A cross-sectional study was conducted in a single tertiary referral hospital in Bali, Indonesia from January 2017 to December 2018. A logistic regression test was used to analyze the factors independently related to mortality. Significantly differences were considered if P-value less than 0.05. A total of 138 children with severe acute malnutrition was fulfilled the study criteria, 83 children $(60.1 \%)$ were male, 79 children $(57.2 \%)$ were a toddler and 133 children $(96.4 \%)$ were classified as marasmus. The mortality was found in 60 children (43.4\%). On multivariate logistic regression analysis found anemia (aOR 8.6, 95\%CI: 2.4 to 30.5, $\mathrm{P}=0.001$ ) and metabolic acidosis (aOR 3.4, 95\%CI: 1.3 to $9.1, \mathrm{P}=0.01$ ) were statistically significant. It can be concluded that the mortality rate among children with severe acute malnutrition is still high and anemia as well as metabolic acidosis are factors independently related to this mortality.
\end{abstract}

International Journal of Health Sciences (C) 2020.

This is an open access article under the CC BY-NC-ND license (https://creativecommons.org/licenses/by-nc-nd/4.0/).

\section{Contents}

Abstract

1 Introduction.

2 Materials and Methods

3 Results and Discussions

4 Conclusion

Acknowledgments.

References

Biography of Authors..

\footnotetext{
a Department of Child Health, Medical Faculty, Udayana University, Denpasar, Indonesia

b Department of Child Health, Medical Faculty, Udayana University, Denpasar, Indonesia

c Department of Child Health, Medical Faculty, Udayana University, Denpasar, Indonesia
} 


\section{Introduction}

Malnutrition is one of the main causes of morbidity and mortality in children and under five (Indonesia Ministry of National Development Planning and United Nations Children's Fund, 2019; Joosten et al., 2008). The prevalence of malnutrition in developed countries ranged from $6.1 \%-11 \%$, while in developing countries it was 6.9\% -53\% (Marino et al., 2006). The status of malnutrition among children under five in Indonesia in 2007,2013 , and 2018 respectively was $6.2 \%, 5.3 \%$, and 3.5\%. The prevalence of malnutrition among children under five in Bali province in 2015, 2016, and 2017 tend to increase from 5.9\%, 5.5\% to 6.3\% (Dinas Kesehatan Provinsi Bali, 2018).

The World Health Organization (WHO) stated that the mortality rate caused by malnutrition accounts for $54 \%$ in children under five. Malnutrition during the last two decades in pediatric intensive care units had increased from $15 \%$ to $65 \%$ with the most dominant comorbid were infection diseases (Kanan et al., 2016). The mortality of malnutrition among children under five in Indonesia was reported at $9.3 \%$ and is associated with many complications (Dinas Kesehatan Provinsi Bali, 2018). Malnutrition has been associated with poor outcomes, including higher rates of infection and complications, impaired wound healing, prolonged length of stay, increased morbidity, and mortality (Allison, 2000; Kubrack et al., 2007).

Children under five years are the most vulnerable population to malnutrition with a greater mortality rate (Chisti et al., 2015). The most frequent type of malnutrition is marasmus. A study found that marasmus accounted for about $77.5 \%$ with a higher mortality rate in marasmus-kwashiorkor type than in marasmus or kwashiorkor type (Derseh et al., 2018). Generally, malnutrition patients are associated with comorbid (Rocha et al., 2006). The most common comorbidities found in malnutrition children were pneumonia (35.4\%), anemia (31.3\%), and tuberculosis (15.4\%) (Arya et al., 2017). Those patients often get enteral nutrition, due to difficulty in sucking and swallowing (Sarni et al., 2009).

Malnourished patients with comorbid usually have longer hospitalization period and associated with several complications (Mena et al., 2018). Anemia generally occurs in malnourished children which is an emergency condition. A study found $65 \%$ of cases of anemia were malnourished children and proved increment of mortality risk to 2.3 times (Cartmel et al., 2005). The acid-base imbalance is a common complication of malnutrition in clinical practice. Metabolic acidosis was frequently found in malnourished children with a higher mortality rate from metabolic acidosis compared to controls (Sharifuzzaman et al., 2017).

Currently, mortality data of malnourished children still emphasize in the group of children under five, but there is not much data on the mortality of malnutrition in children aged 1 month to 18 years old. This study aims to determine the mortality and risk factors for malnourished children aged 1 month to 18 years old who were hospitalized in Sanglah General Hospital.

\section{Materials and Methods}

This study design was an analytical study that used a cross-sectional study design. The study population was malnourished children who were treated in Sanglah General Hospital from January 2017 to December 2018. We got data from the medical records. The sample selection using the total sampling method. The inclusion criteria are children with malnutrition aged 1 month to 18 years old, treated in Sanglah General Hospital, Denpasar during 2017-2018. Exclusion criteria were subjects who had incomplete medical record data. The minimum sample size was 126 patients which were calculated using the formula based on Sastroasmoro \& Ismael (2011).

The data of malnutrition patients was measured using anthropometric measurements according to the regular procedure of the Children's Health Department of Sanglah Hospital. Poor nutrition was defined as a very thin child, characterized by body weight/body height median based on WHO child growth standard 2006 for ages 0-5 years, and/or upper arm circumference $<11.5 \mathrm{~cm}$ in children aged 5-59 months, while children over 5 years of age BW/BH <3rd percentile (p3) CDC 2000 curve or Waterlow $<70 \%$ if there was no organ

Lakonawa, K. Y., Sidiartha, I. G. L., \& Pratiwi, I. G. A. P. E. (2020). Anemia and metabolic acidosis as risk factor of mortality in children with severe acute malnutrition. International Journal of Health Sciences, 4(3), 60-68. https://doi.org/10.29332/ijhs.v4n3.459 
enlargement and the percentage of upper arm circumference to standard arm circumference $<70 \%$ if there was organ enlargement. Marasmus type malnutrition is determined based on clinical condition in which the child looked very thin, old face, wrinkled skin with very little or no fat tissue. Kwashiorkor was determined clinically which was characterized by edema throughout the body, especially feet and hands, moon face, dull hair, and easy to pull out. Marasmus-kwashiorkor was a combination of those signs both found in marasmus and kwashiorkor.

The collected data was recorded in the research form and analyzed using a computer program. A logistic regression test was used to analyze the factors independently related to mortality. Significantly differences were considered if P-value less than 0.05. This research has been approved ethically by the Research and Development body of the Faculty of Medicine, Udayana University/Sanglah Hospital with ethical clearance number 1750/UN14.2.2.VII.14/LT/2020.

\section{Results and Discussions}

Medical record data showed 142 patients with malnutrition, but 4 patients had incomplete medical record data, so the total sample in this study was 138 samples. This study showed 83 children $(60.1 \%)$ were boys with a mortality rate of $41 \%$ ( 34 children). The age group of children under five in this study was 79 children (57.2\%) with a mortality rate of $39.2 \%$ (31 cases).

The most dominant malnutrition type was marasmus with 133 cases (96.4\%) with a mortality rate of $44.4 \%$ (39cases). The most frequent main complaints were dyspnoea in 41 cases $(29.7 \%)$ and fever in 40 cases $(29 \%)$. The most common comorbid found was non-infection with 83 cases $(60.1 \%)$ with a mortality rate $45.8 \%$ (38 cases). The most nutritional route was enteral with 103 cases (74.6\%) with a mortality rate of $31.1 \%$ (32 cases). The length of stay of malnourished patients was generally more than 2 weeks were 84 cases $(60.9 \%)$ with a mortality rate of $44 \%$ (37 cases). Sixteen children $(11.6 \%)$ had hypoglycemia with a mortality rate of $56.2 \%$ ( 9 cases). There were 103 patients with anemia (74.6\%) with a mortality rate of 54.4\% (56 cases). This study found that all samples had acid-base balance disorders with the most dominant cases was metabolic acidosis in 83 cases $(60.1 \%$ ) with a mortality rate of $50.6 \%$ (42 cases). Electrolyte imbalance was found in 92 cases $(66.7 \%$ ) with a mortality rate of $45.7 \%$ (42 cases). Hypoalbuminemia was found in 66 cases $(47.8 \%)$ with a mortality rate of $50 \%$ (33 cases). Ketonuria was found in 14 samples $(10.1 \%)$ with a mortality rate of $42.9 \%$ ( 6 cases) (Table 1$)$.

Table 1

Samples characteristics

\begin{tabular}{lc}
\hline Samples characteristics & $\mathrm{N}=138$ \\
\hline Gender, N (\%) & $83(60.1)$ \\
Male & $55(39.9)$ \\
Female & $79(57.2)$ \\
Age, N (\%) & $59(42.8)$ \\
Toddler & \\
Non-toddler & $133(96.4)$ \\
Types of malnutrition, N (\%) & $5(3.6)$ \\
Marasmus & \\
Kwashiokor & $41(29.7)$ \\
Main complaint while admitted, N (\%) & $40(29)$ \\
Shortness of breath & $17(12.3)$ \\
Fever & $16(11.6)$ \\
Pale & $24(17.4)$ \\
Diarrhea & \\
Others & $55(39.9)$ \\
Comorbid, N (\%) & \\
Infection &
\end{tabular}




$\begin{array}{lc}\text { Non-infection } & 83(60.1) \\ \text { Nutritional route, N (\%) } & \\ \quad \text { Enteral } & 103(74.6) \\ \quad \text { Parenteral } & 35(25.4) \\ \text { Length of stay, N (\%) } & \\ \quad \text { 2 weeks } & 84(60.9) \\ \quad \text { 2 } 2 \text { weeks } & 54(39.1) \\ \text { Random blood sugar, N (\%) } & \\ \quad \text { Hypoglycemia } & 16(11.6) \\ \quad \text { Normal } & 122(88.4) \\ \text { Hemoglobin, N (\%) } & \\ \quad \text { Anemia } & 103(74.6) \\ \quad \text { Normal } & 35(25.4) \\ \text { Blood gas analysis, N (\%) } & \\ \quad \text { Metabolic acidosis } & 83(60.1) \\ \quad \text { Non metabolic acidosis } & 55(39.9) \\ \text { Electrolyte, N (\%) } & \\ \quad \text { Electrolyte imbalance } & 92(66.7) \\ \quad \text { Normal } & 46(33.3) \\ \text { Albumin, N (\%) } & \\ \quad \text { Hipoalbuminemia } & 66(47.8) \\ \quad \text { Normal } & 72(52.2) \\ \text { Keton, N (\%) } & 14(10.1) \\ \quad \text { Ketonuria } & 124(89.9) \\ \quad \text { Normal }\end{array}$

Gender, age, type of malnutrition, comorbid, route of nutrition, length of stay, random blood sugar, electrolytes, albumin, and ketones were not significantly associated with mortality, which their p-value was more than 0.05 . Hemoglobin level and blood gas analysis were found significantly associated with mortality (p-value <0.05).

Multivariate analysis with logistic regression in this study showed that two independent variables associated with mortality. The two variables were hemoglobin level and blood gas analysis. Anemia and metabolic acidosis were significantly and independently associated with mortality (OR 8.63 and 3.44) (Table 2).

Table 2

Non adjusted $\mathrm{OR}$ and Adjusted $\mathrm{OR}$

\begin{tabular}{|c|c|c|c|c|c|c|}
\hline \multirow{2}{*}{ Variables } & \multicolumn{2}{|l|}{ Outcome } & \multirow{2}{*}{$\begin{array}{l}\text { OR } \\
\text { (CI 95\%) }\end{array}$} & \multirow[b]{2}{*}{$\mathrm{p}$} & \multirow{2}{*}{$\begin{array}{l}\text { AOR } \\
\text { (CI 95\%) }\end{array}$} & \multirow{2}{*}{$\mathrm{p}$-value } \\
\hline & Died & Survived & & & & \\
\hline \multicolumn{7}{|l|}{ Gender, N (\%) } \\
\hline Male & $34(41)$ & $49(59)$ & \multirow{3}{*}{$0.77(0.39-1.54)$} & \multirow{3}{*}{0.46} & \multirow{3}{*}{$0.59(0.24-1.47)$} & \multirow{3}{*}{0.26} \\
\hline Female & $26(47.3)$ & $29(52.7)$ & & & & \\
\hline Age, N (\%) & & & & & & \\
\hline Toddler & $31(39.2)$ & $48(60.8)$ & \multirow{2}{*}{$0.67(0.34-1.32)$} & \multirow{3}{*}{0.25} & \multirow{2}{*}{$0.61(0.25-1.48)$} & \multirow{2}{*}{0.28} \\
\hline Non toddler & $29(49.2)$ & $30(50.8)$ & & & & \\
\hline Types of maln & & & & & & \\
\hline Marasmus & $59(44.4)$ & $74(55.6)$ & \multirow{3}{*}{$3.19(0.35-9.30)$} & \multirow{2}{*}{0.28} & \multirow{3}{*}{$1.11(0.09-3.75)$} & \multirow{3}{*}{0.94} \\
\hline Kwashiokor & $1(20)$ & $4(80)$ & & & & \\
\hline Comorbid, N & & & & & & \\
\hline Infection & $22(40)$ & $33(60)$ & \multirow{3}{*}{$0.79(0.39-1.58)$} & \multirow{3}{*}{0.50} & \multirow{3}{*}{$0.69(0.28-1.74)$} & \multirow{3}{*}{0.43} \\
\hline Non infection & $38(45.8)$ & $45(54.2)$ & & & & \\
\hline Nutritional ro & & & & & & \\
\hline
\end{tabular}

Lakonawa, K. Y., Sidiartha, I. G. L., \& Pratiwi, I. G. A. P. E. (2020). Anemia and metabolic acidosis as risk factor of mortality in children with severe acute malnutrition. International Journal of Health Sciences, 4(3), 60-68. https://doi.org/10.29332/ijhs.v4n3.459 


\begin{tabular}{|c|c|c|c|c|c|c|}
\hline $\begin{array}{l}\text { Enteral } \\
\text { Parenteral } \\
\text { Length of stay, N (\%) }\end{array}$ & $\begin{array}{l}32(31.1) \\
28(80)\end{array}$ & $\begin{array}{l}71(68.9) \\
7(20)\end{array}$ & $0.11(0.05-1.29)$ & 0.21 & $0.17(0.02-1.22)$ & 0.31 \\
\hline $\begin{array}{l}\leq 2 \text { weeks } \\
>2 \text { weeks }\end{array}$ & $\begin{array}{l}23(42.6) \\
37(44)\end{array}$ & $\begin{array}{l}31(57.4) \\
47(56)\end{array}$ & $0.94(0.47-1.88)$ & 0.86 & $1.15(0.46-2.85)$ & 0.76 \\
\hline $\begin{array}{l}\text { Random blood sugar, N (\%) } \\
\text { Hypoglycemia } \\
\text { Normal } \\
\text { Hemoglobin, N (\%) }\end{array}$ & $\begin{array}{l}9(56.2) \\
51(41.8)\end{array}$ & $\begin{array}{l}7(43.8) \\
71(58.2)\end{array}$ & $1.79(0.63-5.12)$ & 0.27 & $1.85(0.50-6.80)$ & 0.36 \\
\hline $\begin{array}{l}\text { Anemia } \\
\text { Normal } \\
\text { Blood gas analysis } \mathrm{N}(\%)\end{array}$ & $\begin{array}{l}56(54.4) \\
4(11.4)\end{array}$ & $\begin{array}{l}47(45.6) \\
31(88.6)\end{array}$ & $9.23(3.04-8.05)$ & $0.001^{*}$ & $8.63(2.44-30.51)$ & $0.001^{*}$ \\
\hline Acidosis metabolic & $42(50.6)$ & $41(49.4)$ & & & & \\
\hline $\begin{array}{l}\text { Non acidosis metabolic } \\
\text { Electrolyte, } \mathrm{N}(\%)\end{array}$ & $18(32.7)$ & 37 (67) & $2.11(1.04-4.28)$ & $0.04^{*}$ & $3.44(1.30-9.11)$ & $0.01^{*}$ \\
\hline $\begin{array}{l}\text { Electrolyte imbalance } \\
\text { Normal } \\
\text { Albumin, N (\%) }\end{array}$ & $\begin{array}{l}42(45.7) \\
18(39.1)\end{array}$ & $\begin{array}{l}50(54.3) \\
28(60.9)\end{array}$ & $1,31(0.64-2.69)$ & 0.47 & $0.85(0.33-2.17)$ & 0.73 \\
\hline $\begin{array}{l}\text { Hypoalbuminemia } \\
\text { Normal } \\
\text { Keton, N (\%) }\end{array}$ & $\begin{array}{l}33(50) \\
27(37.5)\end{array}$ & $\begin{array}{l}33(50) \\
45(62.5)\end{array}$ & $1.67(0.85-3.29)$ & 0.14 & $1.68(0.67-4.21)$ & 0.27 \\
\hline $\begin{array}{l}\text { Ketonuria } \\
\text { Normal }\end{array}$ & $\begin{array}{l}6(42.9) \\
54(43.5)\end{array}$ & $\begin{array}{l}8(57.1) \\
70(56.5)\end{array}$ & $0.98(0.32-2.97)$ & 0.96 & $0.34(0.07-1.59)$ & 0.17 \\
\hline
\end{tabular}

*p $<0.05$

\section{Discussion}

This study found that malnutrition was more prevalent in male patients $(60.1 \%)$. This study is in line with the previous study (Rusmil et al., 2018) which states that malnourished were more common in boys by $59 \%$. Another study conducted by Arya et al. also found that the prevalence of malnutrition was higher in males (59\%) (Arya et al., 2017). It also stated that there was no significant relationship between gender and mortality (Arya et al., 2017; Rusmil et al., 2018). This is consistent with the results of this study which the pvalue was 0.46 .

Malnutrition affects individuals in all age groups, but children under five years were the most vulnerable population with greater morbidity and mortality. This age group needs more attention because of greater need for growth and development than other age groups (Chisti et al., 2015) Also, Kusnandi found 58\% of children under 5 years suffered malnutrition (Rusmil et al., 2018). A study by Mena found that 67.3\% of children under 5 were malnourished (Mena et al., 2018). Thus were align with the results of our study, namely that more children under five experienced malnutrition (57.2\%) compared to the non-toddler group. This study showed that there was no significant relationship between age and mortality which was supported by other studies (Mena et al., 2018; Rusmil et al., 2018).

Malnutrition can occur as a result of inadequate nutrition intake, increased demand, impaired absorption, and excessive loss of nutrients (Soeters et al., 2008). Marasmus is caused by a very insufficient intake of nutrients so that the fat tissue in the patient's body was used to produce energy. Generally, the prevalence of marasmus was more frequent than kwashiorkor or marasmus-kwasiokor. It was aligned with Kanan and Swar who found marasmus 68.6\%, kwashiorkor 23.8\%, and marasmus-kwashiorkor 7.6\% (Kanan et al., 2008). Another study found the prevalence of marasmus $77.5 \%$ followed by kwashiorkor 16\%, marasmus- 
kwashiorkor 6.5\% (Derseh et al., 2018) The study also found a higher mortality rate in marasmuskwashiorkor type compared to marasmus or kwashiorkor types, but there was no relationship between mortality and this type of malnutrition (Derseh et al., 2018; Tesfai et al., 2013; Thakur et al., 2014). Our study found that the most severe type of malnutrition was marasmus (96.4\%) however no significant relationship between the type of malnutrition and mortality was found. The factors that influence the type of malnutrition in a child are multifactorial.

Malnutrition is related to basic disease or as a complication of comorbid disease or could be a combination of the two factors (Soeters et al., 2008). This study found that the most dominated comorbidities were noninfectious disease (60.1\%). Also, Mena found that the most dominant comorbid were non-infectious (53.2\%) (Mena et al., 2018). However, another study showed different results which the most dominant comorbid was pneumonia 35.4\% followed by anemia 31.3\% (Rusmil et al., 2018). Also, another study found that acute respiratory infections and tuberculosis were the most common comorbidities in children with malnutrition at 26.5 and 21.5\% (Arya et al., 2017). Malnutrition and respiratory infections have strong and consistent associations, with malnutrition being considered as a risk factor for pneumonia. Malnutrition with respiratory infections is associated with increased mortality (Arya et al., 2017; Rusmil et al., 2018). Our study found no significant association between comorbid and mortality. The results of our study were different from previous studies which can be caused by differences in the age range of our samples, which the previous study used sample aged 6 months to 5 years old, while this study examined sample aged 1 month to 18 years old with malignancy as the most dominant cases.

Our study found that the most dominant nutritional route was enteral as much as $74.6 \%$. This result was in line with the study by Wagnew which enteral nutrition was 66.7\% (Wagnew et al., 2018). The study by Sarni showed that the most dominant nutrition was oral route $80.3 \%$, enteral $13.4 \%$, and parenterally $6.3 \%$ (Sarni et al., 2009). Indication of enteral nutrition was sucking and swallowing difficulty, which could be found in patients with respiratory disorders (Sarni et al., 2009). In this study, there was no significant relationship between the route of nutrition and mortality.

The length of stay is related to the patient's comorbidities. A long treatment period was one of the factors associated with bodyweight decrement during hospitalization (Tadesse et al., 2018). The majority of the length of stay in this study was $>2$ weeks $(60.9 \%)$. This result was in line with Tadesse which found that $71.4 \%$ of malnourished children were hospitalized for more than 2 weeks (Tadesse et al., 2018). Also, Mena found similar results length of stay for malnourished children more than 14 days was 53.3\% (Mena et al., 2018; Pinto et al., 2017). The study found that there was no significant relationship between mortality and length of stay with p-value 0.27; OR 2.53 (CI 95\% 0.48-13.16).15 in this study there was no significant relationship between the length of stay and mortality $(p=0.86)$.

Hypoglycemia is a complication of malnutrition. This can be caused by the severity of the disease or comorbidities on admission to the hospital. Research on the relationship between hypoglycemia and mortality in malnutrition has not been widely found. Hypoglycemia represents a poor prognosis for malnutrition (Ali et al., 2017). This study found hypoglycemia in $11.6 \%$ of cases. Research by Ali found that $14 \%$ of malnourished children experienced hypoglycemia (Ali et al., 2017). Another study also found a similar case, namely the prevalence of hypoglycemia in malnourished children 26.6\% (Barennes et al., 2016). In this study, there was no significant relationship between hypoglycemia and mortality.

Anemia generally occurs in malnourished children whose severe anemia is an emergency. This study found $74.6 \%$ of children had anemia. Research by Ali found that $88.3 \%$ of malnourished children were anemic (Ali et al., 2017). A study by Mena found that $71.2 \%$ of malnourished children had anemia and there was a significant relationship between anemia and mortality ( $\mathrm{p}=0.001$, OR 7.82, 95\% CI $2.74-22.29$ ) (Mena et al., 2018). Cartmell also found $65 \%$ of cases of anemia in malnourished children and proved the relationship between anemia and mortality with $\mathrm{p}=0.001$. This study found a significant relationship between anemia and mortality with $\mathrm{p}=0.001$ (Cartmell et al., 2005).

Multivariate analysis in this study found anemia was significantly and independently associated with the risk of mortality. Malnourished children who have anemia have a risk of death 8.63 times greater than those of malnourished children who are not anemic with an AOR of 8.63 (CI95\% 2.44-30.51) p-value of 0.001. Another study found similar results in which anemia increased the risk of death 2.37 times (95\% CI 1.24-4.51) with a p-value of 0.023-0.21

Lakonawa, K. Y., Sidiartha, I. G. L., \& Pratiwi, I. G. A. P. E. (2020). Anemia and metabolic acidosis as risk factor of mortality in children with severe acute malnutrition. International Journal of Health Sciences, 4(3), 60-68. https://doi.org/10.29332/ijhs.v4n3.459 
Malnutrition can cause a persistent increase in acid load which can affect the function of all cells in our body. Children who experience malnutrition will experience changes in the acid-base balance, which is one of the factors causing increased morbidity and mortality in malnourished children. Metabolic acidosis is the most common disorder in malnutrition (Shah et al., 2007).

This study found that all samples had acid-base imbalance with the most dominant cases was metabolic acidosis $(60.1 \%)$. This result aligns with the study by Shah et al. which found all patients $(100 \%)$ had an acidbase balance disorder with 94\% metabolic acidosis and 6\% metabolic alkalosis (Shah et al., 2007). The study found that mortality was significantly associated with metabolic acidosis, hyponatremia, and hyponatremia with hypokalemia compared with the normal group (Shah et al., 2007). Another study by Sharifuzzaman et al. found $51.1 \%$ had metabolic acidosis and the rest without metabolic acidosis, with a higher mortality rate in the metabolic acidosis (53\%) compared with the control $(29 \%)(\mathrm{p}=0.01)$ (Sharifuzzaman et al., 2017). This study found a significant relationship between metabolic acidosis and mortality with a p-value of 0.04 . Multivariate analysis of this study found metabolic acidosis was significantly associated with the risk of death. Malnourished children who experienced metabolic acidosis had a risk of death 3.44 times greater than malnourished children who did not experience metabolic acidosis with an AOR of 3.44 (95\% CI 1.30-9.11) pvalue 0.01 .

This study found an electrolyte balance disorder of $66.7 \%$. The study by Shah found $80 \%$ of patients had electrolyte balance disorders with 56\% hyponatremia, $46 \%$ hypokalemia, $26 \%$ hyponatremia with hypokalemia, 10\% hypernatremia, 3\% hyperkalemia, and 37\% impaired electrolyte balance (Shah et al., 2007). The study found that mortality was significantly associated with hyponatremia, hyponatremia with hypokalemia compared with the normal group. These results are different from this study wherein this study there was no significant relationship between electrolyte balance disorders and mortality. This difference can be caused by the variable category in this study which is limited to the electrolyte balance disorder and normal categories.

This study found $47.8 \%$ hypoalbuminemia and $10.1 \%$ ketonuria. A study by Abdullahi found that $47.1 \%$ of malnourished children had hypoalbuminemia with a low serum total protein level of $49.2 \%$ compared to controls (Abdullahi et al., 2018). These low levels of total serum protein and albumin can be caused by protein deficiency that causes synthesis disorders. Patients with malnutrition with low carbohydrate intake will experience a catabolic process. The liver will convert fat into acetone as fuel by the muscles when the body lacks glucose. Ketone bodies are used by the extrahepatic tissue as fuel to produce energy. Acetoacetate and 3hydroxybutyrate are carried from the liver to the extrahepatic tissue, for example, through the blood circulation. Acetoacetic acid and 3-hydroxybutyric acid are medium strength acids that will be balanced if they are present in blood or tissues, however, if the two keton bodies are released continuously in large amounts, there will be ketonemia and ketonuria (Abdullahi et al., 2018).

\section{Conclusion}

This study found that anemia and metabolic acidosis were common conditions in malnourished children and there was a significant relationship between anemia and mortality $(p=0.001)$, and metabolic acidosis and mortality $(p=0.04)$. Anemia and metabolic acidosis are risk factors for mortality in malnourished children. Malnourished children with anemia had a risk of death 8.63 times greater than malnourished children without anemia. Malnourished children with metabolic acidosis had a risk of death 3.44 times greater than malnourished children without metabolic acidosis. The results of this study were more or less consistent with the findings in previous studies, however, it must be noted that there was insufficient data regarding the relationship between variables.

\section{Acknowledgments}

We are grateful to two anonymous reviewers for their valuable comments on the earlier version of this paper. 


\section{References}

Abdullahi, S. M., Yakubu, A. M., Bugaje, M. A., \& Akuyam, S. M. (2018). Serum total protein and albumin levels among malnourished children aged 6-59 months in Zaria. Nigerian Journal of Paediatrics, 45(1), 15-18.

Ali, S. M., \& Meshram, H. S. (2017). Association of azotemia with hypoglycemia in severe acute malnutrition how much concerning?. International Journal of Contemporary Pediatrics, 4(1), 246.

Allison, S. P. (2000). Malnutrition, disease, and outcome. Nutrition (Burbank, Los Angeles County, Calif.), 16(78), 590-593.

Arya, A. K., Kumar, P., Midha, T., \& Singh, M. (2017). Hematological profile of children with severe acute malnutrition: a tertiary care centre experience. Int J Contemp Pediatr, 4(5), 1577-80.

Barennes, H., Sayavong, E., \& Pussard, E. (2016). High mortality risk in hypoglycemic and dysglycemic children admitted at a referral hospital in a non malaria tropical setting of a low income country. PloS one, 11(2), e0150076.

Cartmell, E., Natalal, H., Francois, I., Ferreira, M. H., \& Grahnquist, L. (2005). Nutritional and clinical status of children admitted to the malnutrition ward, Maputo central hospital: a comparison of data from 2001 and 1983. Journal of tropical pediatrics, 51(2), 102-105.

Chisti, M. J., Salam, M. A., Bardhan, P. K., Faruque, A. S., Shahid, A. S., Shahunja, K. M., ... \& Ahmed, T. (2015). Severe sepsis in severely malnourished young Bangladeshi children with pneumonia: a retrospective case control study. PLoS One, 10(10), e0139966.

Derseh, B., Mruts, K., Demie, T., \& Gebremariam, T. (2018). Co-morbidity, treatment outcomes and factors affecting the recovery rate of under-five children with severe acute malnutrition admitted in selected hospitals from Ethiopia: retrospective follow up study. Nutrition journal, 17(1), 116.

Dinas Kesehatan Provinsi Bali. (2018). Profil Kesehatan Dinas Kesehatan Provinsi Bali 2018.

Indonesia Ministry of National Development Planning and United Nations Children's Fund, (2019), Achieving the SDGs for children in Indonesia: Emerging findings for reaching the targets.

Joosten, K. F., \& Hulst, J. M. (2008). Prevalence of malnutrition in pediatric hospital patients. Current opinion in pediatrics, 20(5), 590-596.

Kanan, H. R., Faez, K., \& Gao, Y. (2008). Face recognition using adaptively weighted patch PZM array from a single exemplar image per person. Pattern Recognition, 41(12), 3799-3812. https://doi.org/10.1016/j.patcog.2008.05.024

Kanan, S. O., \& Swar, M. O. (2016). Prevalence and outcome of severe malnutrition in children less than fiveyear-old in Omdurman Paediatric Hospital, Sudan. Sudanese Journal of Paediatrics, 16(1), 23.

Kementrian Kesehatan Republik Indonesia, (2010), Hasil Utama Riskesdas 2010 [online].

Kubrak, C., \& Jensen, L. (2007). Malnutrition in acute care patients: a narrative review. International journal of nursing studies, 44(6), 1036-1054. https://doi.org/10.1016/j.ijnurstu.2006.07.015

Marino, L. V., Goddard, E., \& Workman, L. (2006). Determining the prevalence of malnutrition in hospitalised paediatric patients. South African Medical Journal, 96(9), 993-995.

Mena, M. B., Dedefo, M. G., \& Billoro, B. B. (2018). Treatment outcome of severe acute malnutrition and its determinants among pediatric patients in West Ethiopia. International journal of pediatrics, 2018.

Pinto, F., Suwiyoga, I. K., Widiana, I. G. R., \& Yasa, I. W. P. S. (2017). Health behavior and status related to mother's death in Timor-Leste. International research journal of engineering, IT \& scientific research, 3(4), 57-65.

Rocha, G. A., Rocha, E. J., \& Martins, C. V. (2006). Hospitalização: efeito sobre o estado nutricional em crianças. Jornal de Pediatria, 82(1), 70-74.

Rusmil, V. K., Wiramihardja, S., Adhitya, A. P., \& Gurnida, D. A. (2018). Factors Influencing Outcomes of Children Hospitalized with Acute Severe Malnutrition. Althea Medical Journal, 5(2), 87-92.

Sarni, R. O., Carvalho, M. D. F., Monte, C. M., Albuquerque, Z. P., \& Souza, F. I. (2009). Anthropometric evaluation, risk factors for malnutrition, and nutritional therapy for children in teaching hospitals in Brazil. J Pediatr (Rio J), 85(3), 223-8.

Sastroasmoro, S., \& Ismael, S. (2011). Dasar-dasar metodologi penelitian klinis. Jakarta: sagung seto, 55.

Shah, G. S., Das, B. K., Kumar, S., Singh, M. K., \& Bhandari, G. P. (2007). Acid base and electrolyte disturbance in diarrhoea. Kathmandu University medical journal (KUMJ), 5(1), 60-62.

Lakonawa, K. Y., Sidiartha, I. G. L., \& Pratiwi, I. G. A. P. E. (2020). Anemia and metabolic acidosis as risk factor of mortality in children with severe acute malnutrition. International Journal of Health Sciences, 4(3), 60-68. https://doi.org/10.29332/ijhs.v4n3.459 
Sharifuzzaman, Sarmin, M., Ahmed, T., Alam, T., Islam, S. B., Islam, M. M., \& Chisti, M. J. (2017). Determinants and outcome of metabolic acidosis in diarrheal children under 5 years of age in an urban critical care ward in Bangladesh. Global Pediatric Health, 4, 2333794X17740223.

Soeters, P. B., Reijven, P. L., Schols, J. M., Halfens, R. J., Meijers, J. M., \& van Gemert, W. G. (2008). A rational approach to nutritional assessment. Clinical nutrition, 27(5), https://doi.org/10.1016/j.clnu.2008.07.009

Tadesse, E., Worku, A., Berhane, Y., \& Ekström, E. C. (2018). An integrated community-based outpatient therapeutic feeding programme for severe acute malnutrition in rural Southern Ethiopia: Recovery, fatality, and nutritional status after discharge. Maternal \& child nutrition, 14(2), e12519.

Tesfai, C., Ratnayake, R., \& Myatt, M. (2013). Measuring local determinants of acute malnutrition in Chad: a case-control study. The Lancet, 381, S144. https://doi.org/10.1016/S0140-6736(13)61398-7

Thakur, N., Chandra, J., Pemde, H., \& Singh, V. (2014). Anemia in severe acute malnutrition. Nutrition, 30(4), 440-442. https://doi.org/10.1016/j.nut.2013.09.011

Wagnew, F., Tesgera, D., Mekonnen, M., \& Abajobir, A. A. (2018). Predictors of mortality among under-five children with severe acute malnutrition, Northwest Ethiopia: an institution based retrospective cohort study. Archives of Public Health, 76(1), 64.

\section{Biography of Authors}

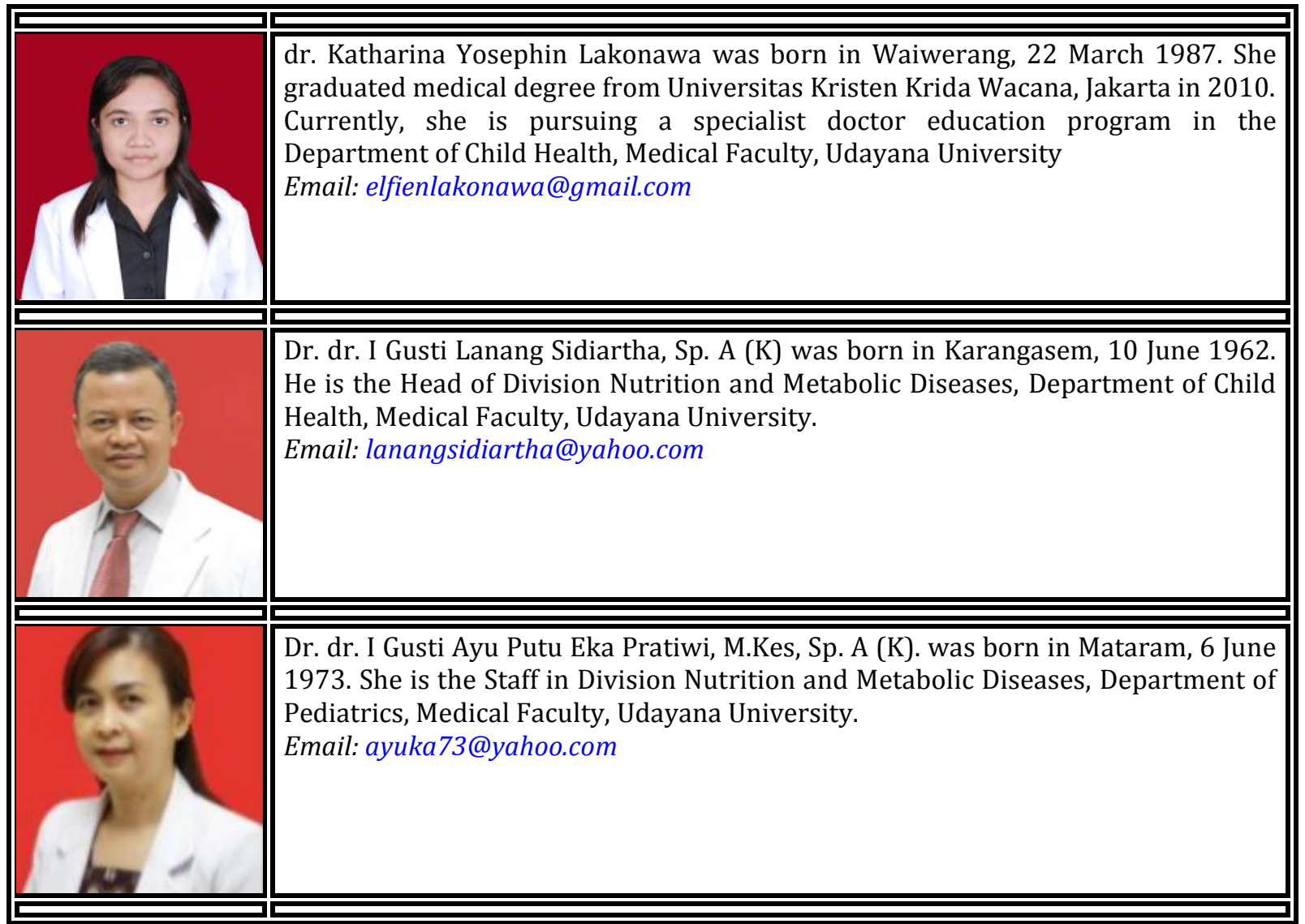

